\title{
Telomere and Telomerase: Biological Markers of Organic Vital Force State and Homeopathic Treatment Effectiveness
}

\author{
Marcus Zulian Teixeira1® \\ ${ }^{1}$ School of Medicine, University of São Paulo, São Paulo, Brazil \\ Homeopathy 2021;110:283-291.
}

\author{
Address for correspondence Marcus Zulian Teixeira, MD, PhD, Rua \\ Teodoro Sampaio, 352/128, 05406-000, São Paulo/SP, Brazil \\ (e-mail: marcus@homeozulian.med.br).
}

\begin{abstract}
Keywords

- homeopathy

- vitalism

- genetics

- telomere

- telomerase

- biomarker

Background Philosophical-scientific correlations described in previous studies suggest that the genome can be the biological representation of the vital force, whilst the disease-promoting epigenetic alterations would be the biological representation of the chronic miasmas. In this study, we expand the functional correlation between vital force and chromosomes, describing the mechanism of action of the telomeretelomerase complex in the context of physiological balance.

Aims The aim of the work is to study the role of the telomere-telomerase complex in cell vitality, biological aging, and the health-disease process, with the goal of proposing the use of telomere length as a biomarker of the vital force state and the effectiveness of homeopathic treatment.

Results Similar to the vital force, telomere length and telomerase enzyme activity play an important role in maintaining cellular vitality, biological longevity, and physiological homeostasis. Telomere shortening functions as a biomarker of vital imbalance and is associated with numerous diseases and health disorders. On the other hand, health-promotion practices neutralize the pathological shortening of the telomeres, acting therapeutically in diseases or age-dependent health disorders.

Conclusions As a hypothetical biomarker of the vital force state, an intra-individual analysis of the mean leukocyte telomere length before, during, and after homeopathic treatment can be used as a biomarker of therapeutic effectiveness.
\end{abstract}

\section{Introduction}

According to the homeopathic model, the primary cause of diseases is an imbalance of the organic vital force, whilst the return to health status occurs by restoring the integrity of this vital principle. Homeopathy expands understanding of the health-disease process and also attributes the manifestation of chronic diseases to the action of chronic miasms, a fundamental cause and main obstacle to the natural resolution of these diseases.

received

November 3, 2020 accepted after revision

December 3, 2020

published online

May 16, 2021
DOI https://doi.org/ 10.1055/s-0041-1726008. ISSN 1475-4916.
According to the biomedical model, the vital functions of the physical body are controlled by biochemical information contained in the DNA or genome (exome plus epigenome), with the primary cause of diseases being located in the genes encoding physiological disorders that cause disease. In turn, these disease-promoting gene expressions are modulated by the epigenome, a portion of the noncoding protein DNA that regulates the coding portion (exome) and is a fundamental cause for the manifestation of chronic diseases in general.

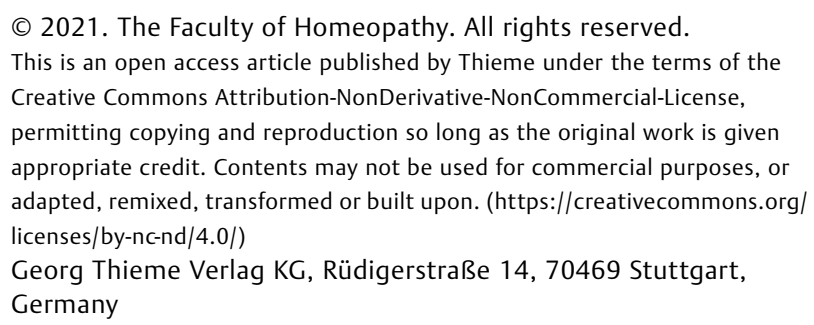


Based on conceptual, functional, and experimental correlations described in previous studies, ${ }^{1,2}$ we have suggested that the genome (exome plus epigenome) can be the biological representation or substrate of the vital force or principle, and the disease-promoting epigenetic alterations would be the representation or the biological substrate of chronic miasmas. Further based on these assumptions, we have also been proposing the isopathic use of auto-sarcode of DNA (autoisotherapic of DNA) as a probable anti-miasmatic homeopathic medicine and modulator of gene expression. ${ }^{1,2}$

Reiterating these philosophical-scientific correlations, numerous studies on telomeres (the terminal portion of chromosomes) indicate its role as a biomarker of cellular vitality, biological aging, and the health-disease process. In view of this evidence, telomere length $(\mathrm{TL})$ could be clinically and experimentally used as a hypothetical biomarker of the organic vital force state, both in the disease-promoting vital imbalance and in the vital rebalancing resulting from therapeutic interventions.

In this review, we will discuss the mechanisms of action of telomeres and the telomerase enzyme in the integrity of chromosomes, in the vitality or senescence of cells, in the longevity or aging of the body, and in the healthy or disease state. Based on the influence of health promotion treatments and practices on telomeric homeostasis, we are suggesting using $\mathrm{TL}$ as a possible biological parameter to assess the organic vital force state and the effectiveness of homeopathic treatment.

\section{Aims}

The objective of this article is to study the mechanism of action of telomeres and the telomerase enzyme in the integrity of chromosomes, in cellular vitality, in biological aging, and in the health-disease process, proposing to use TL as a biomarker of the organic vital force state and the effectiveness of homeopathic treatment in order to expand the philosophical-scientific correlations of homeopathic vitalism with modern genetics, as widely discussed in previous studies. ${ }^{1,2}$

\section{Cause of Diseases According to the Homeopathic Model}

\section{Imbalance of Vital Force As a Primary Cause of Diseases}

According to the Hahnemannian vitalist philosophical concept, ${ }^{3,4}$ the homeopathic vital force resembles the hippocratic vis medicatrix naturae, manifesting itself automatically and instinctively, and being subject to the laws of the physical body. The vital force has the property to maintain life and the balance of sensations and physiological functions (homeostasis) but loses this capacity with aging or the onset of a disease process.

In understanding the health-disease process according to the homeopathic model, the primary cause of the body's diseases is located in the imbalance or dystonia of the organic vital force as a result of the dynamic influence of diseasepromoting agents. On the other hand, healing and a return to health occur by restoring the integrity of the vital principle (Organon der Heilkunst, 6th ed., paragraphs 11, 12). ${ }^{5}$

In view of its dynamic and non-material nature, the vital force is influenced by subtle manifestations of the mind and the psyche such as thoughts, emotions and feelings (Organon, paragraphs $213-216$ ). ${ }^{5}$ The vital principle is also weakened by an inadequate lifestyle (sedentary, alcohol and drugs, unbalanced diet, intellectual and sexual excesses, among others), and is restored by health-promotion practices (physical exercise, alcohol and drug abstinence, adequate diet and mental distraction, among others) (Organon, paragraphs 260-262). ${ }^{5}$

In view of its similar nature, the dynamized or potentized homeopathic medicine is able to restore vital harmony (Organon, paragraph 16), ${ }^{5}$ provided that it is used according to the principle of therapeutic similarity, awakening a curative vital reaction.

According to homeopathic vitalist anthropology, ${ }^{6}$ the irrational vital force differs in nature and species from the intelligent spirit, which is defined as an autonomous entity and separate from the inseparable physical-vital unit. Hahnemann did not deepen his understanding of the intimate nature or essence of the organic vital force, although he considered it the primary cause (prima causa morbi) of diseases (Organon, paragraphs $6-13) .^{5}$

The homeopathic vitalist model presents a set of concepts, entities and properties that are similar to other medical and philosophical concepts, ${ }^{4,6}$ such as traditional Chinese medicine, traditional Indian medicine, and anthroposophical medicine.

\section{Chronic Miasms As a Fundamental Cause of Diseases}

In the work The Chronic Diseases, their Peculiar Nature, and their Homeopathic Cure, ${ }^{7}$ Hahnemann includes the influence of three chronic and dynamic miasmas in the etiopathogenesis of chronic diseases (psora, sycosis and syphilis), imputing the main obstacle to the cure of these diseases to them. He attaches special importance to psora (the Itch disease), which he considered to be "the oldest and most Hydra-headed of all the chronic miasmatic diseases" and from which "at least seven-eighths of all the chronic maladies" originate (The Chronic Diseases, pp. 7-13). ${ }^{7}$

Reiterating what was previously described, Hahnemann describes a series of aspects, in the chapter "Cure of the Chronic Diseases", sub-section "Psora", that weaken the organic vital force (such as inadequate lifestyle and diet, temperature change, lack of physical activity or excess of mental activity, sexual excesses, trauma, acute infectious diseases, use of drugs and alcohol, smoking, inappropriate medicines and treatments, emotional and psychic disorders) and "can bring the psora latent and slumbering to break out into open chronic diseases" (The Chronic Diseases, pp. 107-114). ${ }^{7}$

In the same chapter, sub-section "The Medicines", Hahnemann indicates that the previous use of specific homeopathic medicines (anti-miasmatics) would act on these "too inveterate and more deep-seated" chronic diseases before administering the homeopathic medicines chosen according to the totality of symptoms characteristic of the classic approach in order to be successful to cure and end these diseases to their fullest extent. 
Maintaining the conceptual coherence, Hahnemann describes these same characteristics and properties of chronic miasms in Organon (Introduction; paragraphs 5, 72-81 and 204-206), ${ }^{5}$ denominating psora as "the only real fundamental cause and producer of all forms of disease" or "causam morborum chronicum".

\section{The Cause of Diseases According to the Biomedical Model}

According to the biomedical model, the body's vital functions are essentially controlled by biochemical information contained in the DNA of the cells (set of nucleotide sequences), which transmits these characteristics to future generations and undergoes mutations that allow evolutionary adaptations in the face of various environmental factors.

This genetic material or cellular genome is contained in highly organized nuclear structures called chromosomes formed by extremely long DNA molecules that contain several genes and other nucleotide sequences with specific functions, being closely related to gender determination and genetic inheritance. In eukaryotic beings, somatic cells have 23 pairs of chromosomes (46 chromosomes), while sex cells or gametes have only one copy of each chromosome (23 chromosomes).

The genome is composed of the exome (the portion of DNA encoding proteins necessary for maintaining and controlling physiological functions) and the epigenome (the portion of non-coding DNA that regulates the expression of the encoding genes). In turn, physiological imbalances and most chronic diseases manifest as a direct reflection of changes in the patterns of this gene expression.

Epigenetic alterations (DNA methylation, histone acetylation, and micro-RNAs, among others) make up a set of enzyme-mediated chemical processes, which represent an additional mechanism for regulating gene expression at the transcriptional level, shaping genome functioning and the phenotypic profile through the activation or deactivation of genes, without any change in the nucleotide sequence of the genetic code. ${ }^{8,9}$

The individual epigenome is transmitted to future generations according to a specific epigenetic code (transgenerational epigenetic susceptibility), influencing the descendant's health-disease process. ${ }^{10,11}$ This epigenotype functions as highly interconnected regulatory networks (complex systems of self-organization), and gives the genome instructions for when and where genes should be expressed.

In addition to being reversible, these epigenetic alterations can be expressed in the genome of individuals at any age, as long as they come into contact with internal and/or external etiopathogenic stimuli (for example, habits and inadequate lifestyle, pollution and irradiation, drugs and hormones, inflammation, stress and emotions), promoting the activation or silencing of genes responsible for manifesting diseases. ${ }^{8,11-16}$

Therefore, the genome (exome plus epigenome) must be considered as the primary cause of diseases in general, and the specific aspects related to each individual case of illness are represented in the disease-promoting epigenetic alterations (fundamental cause of chronic diseases).

\section{Philosophical-Scientific Correlations between Vital Force and Genome and between Chronic Miasms and Epigenetic Alterations}

In correlating the characteristics of the organic vital force with those of the genome, we highlight analogies between them, such as: the vital force and the genome are the fundamental substrates for the emergence and maintenance of life (vitality of living beings); the vital principle is responsible for maintaining the balance of the body's sensations and functions, just as the genome stores the biochemical information which will produce the proteins responsible for maintaining vital processes and developing organisms; diseases generally occur due to dystonia of the vital principle, as well as genomic changes which promote disease (the primary cause of diseases); the vital force and the genome are both affected by the influences of the same external and internal etiopathogenic factors, among others. ${ }^{2}$

Furthermore, in correlating the characteristics of chronic miasms with those of epigenetic alterations, we highlight analogies between them, such as: most chronic diseases have a miasmatic (psora) or epigenetic cause which predisposes their appearance and prevents their natural resolution (fundamental cause of chronic diseases); the latency or manifestation of psora and the silencing or activation of disease-promoting genes are triggered by similar etiopathogenic factors; both chronic miasmas and disease-promoting epigenetic alterations are transmissible to future generations, and can be reversed by antimiasmatic drugs or epigenetic treatments, respectively. ${ }^{1}$

Since 1997, Khuda-Bukhsh ${ }^{17-19}$ and other researchers $^{20,21}$ defend the hypothesis that homeopathic medicines act in the genome, modulating disease-promoting gene expression. In this context, dozens of in vitro experimental studies suggest that potentized homeopathic medicines may act in the homeostatic regulation of gene expression, in view of their causing apoptosis in cancer cells and therapeutic regulation in disease-promoting gene expression. ${ }^{1}$

Therefore, we can correlate the intrinsic characteristics and properties of the homeopathic vital principle to those of the genome (exome plus epigenome), suggesting the hypothesis that this is the representation or biological substrate of that according to the biomedical model. ${ }^{2}$ On the other hand, disease-promoting epigenetic alterations would be the representation or biological substrate of chronic homeopathic miasmas. ${ }^{1}$

In short, in homeopathic terms, the genome would be the simillimum of organic vital force and the disease-promoting epigenetic alterations would be the simillimum of chronic miasmas.

In accordance with these hypotheses, the isopathic use of auto-sarcode of DNA (auto-isotherapic of DNA) could act on the imbalance of the vital principle or genome, and in the chronic miasmas or disease-promoting epigenetic alterations, through therapeutic modulation of gene expression. ${ }^{1,2}$ 


\section{Telomere and Telomerase: Biological Markers of Cellular Vitality, Biological Aging, and Health-Disease Process}

Cellular activity and vitality are related to physiological balance and health-disease process. Its natural and progressive decrease causes a decline in physiological functions and in the body's ability to adapt, causing biological aging and a predisposition to the appearance of diseases. Both the senescence process and the manifestation of diseases are influenced by genetics, epigenetics, and environmental factors that impact the quality of life. In this dynamic complexity, the TL and the activity of the telomerase enzyme are biological markers of cellular vitality, aging, and the health-disease process.

In 2009, Elizabeth Blackburn, Carol Greider and Jack Szostak received the Nobel Prize in Physiology or Medicine for discovering the role of telomeres and the telomerase enzyme in the integrity of chromosomes and genetic information. ${ }^{22,23}$ These discoveries paved the way for researchers to broaden their understanding of the role of telomeres in the biological aging process and in the development of chronic diseases in general, noting that telomere attrition is influenced by oxidative damage and replicative stress caused by genetic, epigenetic, and environmental factors.

Just like epigenetic alterations, telomeres are non-coding regions of the genome that are located at the ends of chromosomes, consisting of long series of short and repeated sequences formed by the 5'-TTAGGG-3' nitrogenous bases and associated proteins, and play an important role in the maintenance and integrity of DNA. Telomere shortening functions as a cellular vitality marker, and compromises the replicative potential of cells, thereby contributing to the natural process of cellular senescence. In order to counteract this process, the telomerase enzyme promotes maintenance of the TL by synthesizing the repetitive sequences of the lost telomeric DNA.

During cell division (phase S), cells are unable to replicate around 50 to 200 pairs of nitrogenous bases at the ends of the chromosomes as the DNA polymerase enzyme cannot reproduce the 3' end of the linear molecule ("final replication problem"). This leads to the progressive shortening of chromosomes along with cell divisions, resulting in loss of replication capacity and induction of cell senescence. This mechanism is the main cause of aging and age-related chronic diseases. ${ }^{24-26}$

In order to avoid this progressive shortening of telomeres, which occurs with each cell division and the respective loss of genetic information, the lost DNA segments are periodically recovered thanks to a ribonucleoprotein enzyme complex called telomerase, comprising the telomerase RNA component (TERC) and the telomerase reverse transcriptase (TERT). Under TERT's action, TERC constitutes a template for synthesizing the repetitive sequences that compose the telomere. In the recovery of the lost telomeric DNA, this RNA template is positioned over the initiator DNA, the nitrogenous bases are added individually and in the correct sequence; then telomerase translocates at the end of the process to restart the process. ${ }^{26-28}$
Telomerase activity in the neonatal period is reduced or null and is absent in most somatic tissues in the body. Telomerase is active in the early stages of human development (pluripotent embryonic cells) and throughout life in blood stem cells, germ cells, and adult tissues in continuous renewal (endometrial tissue, for example). ${ }^{29}$ The telomeric terminals of the cells are shortened in each cell division as a result of the gradual loss of telomerase activity, reaching a minimum length that makes cell division impossible. ${ }^{30}$

As tissues undergoing continuous renewal, $90 \%$ of somatic cancer cells exhibit high telomerase expression, maintaining $\mathrm{TL}$ and achieving "immortality". In these cancer cells, the reactivation of the telomerase silencing gene has been one of the mechanisms used to circumvent the natural system of cellular senescence and apoptosis, allowing them to continue promoting the lengthening of the telomeres and to replicate in an uncontrolled and uninterrupted manner. ${ }^{31,32}$

In demonstrating the relationship between TL and health disorders, numerous studies show that shorter telomeres are associated with a number of chronic diseases. These diseases include: congenital dyskeratosis, aplastic anemia, idiopathic pulmonary fibrosis, and liver cirrhosis ${ }^{33}$; cardiovascular diseases in general, ${ }^{34,35}$ such as atherosclerosis, ${ }^{36,37}$ arterial hypertension $^{38}$ and stroke ${ }^{39}$; type 2 diabetes mellitus ${ }^{40,41}$; autoimmune diseases such as systemic lupus erythematosus ${ }^{42}$ and rheumatoid arthritis ${ }^{43}$; psychiatric disorders ${ }^{44,45}$ and neurological conditions ${ }^{46,47}$, among other age-related diseases. ${ }^{48}$

Acquired chronic infectious diseases such as HIV ${ }^{49,50}$ also promote telomere shortening. Even in acute infectious diseases, such as the current COVID-19, telomere shortening is proposed as a marker of disease severity and can identify patients at risk of higher morbidity and mortality from SARSCoV-2 infection. ${ }^{51,52}$ Studies suggest that T-cell lymphopoiesis may be discontinued in individuals with short telomeres that have been infected. ${ }^{53}$

The same telomere shortening is observed in other health disorders, addictions or intoxications, such as obesity, ${ }^{54}$ metabolic syndrome, ${ }^{55}$ inflammatory and oxidative processes, ${ }^{56}$ smoking, ${ }^{57}$ alcoholism ${ }^{58}$ and drug addiction, ${ }^{59}$ or exposure to pollutants and mineral particles. ${ }^{60}$

In addition, traumatic social exposures or psycho-emotional disorders experienced throughout life, such as chronic stress $^{61,62}$ and childhood trauma (for example, abuse, violence, racism, bullying, low socio-economic status, maternal depression, family disturbance, institutionalization $)^{63-66}$ also cause a decrease in TL.

TL has a double role in cancer: telomere shortening can lead to induced chromosomal instability and the beginning of tumor formation (pre-cancerous lesion); on the other hand, initiated tumors need to reactivate telomerase to stabilize chromosomes and achieve "immortal" growth capacity. ${ }^{67-69}$

Studies show a decrease in the size of telomeres associated with chronic health disorders in cancer survivors as a collateral effect of cancer treatment (radiotherapy and chemotherapy). ${ }^{70}$ Similarly, other drugs demonstrate the same collateral effect of telomere shortening (immunosuppressants, ${ }^{71}$ proton pump inhibitors, ${ }^{72}$ insulin, ${ }^{73}$ and hypnotics, ${ }^{74}$ among others). 
On the other hand, some therapies are being assessed to counteract telomere shortening and act on telomere diseases: for example, sex hormones (aplastic anemia and idiopathic pulmonary fibrosis), ${ }^{33,75}$ anti-diabetic agents without acarbose (type 2 diabetes), ${ }^{76}$ and lithium (bipolar disorder). ${ }^{77}$ Similarly, natural compounds and their extracts have been shown to increase telomerase activation (Astragalus membranaceus or TA-65, Centella asiatica, Euterpe oleracea, oleanolic acid, maslinic acid, and multi-nutrient formulas), ${ }^{33,78,79}$ which may be indicated in treating diseases related to telomere shortening.

Given that most cancer cells present increased telomerase activity, different anti-cancer approaches have been designed in the search for telomerase inhibitors: small-molecule inhibitors, anti-sense oligonucleotides (imetelstat), G-quadruplex stabilizers, immunotherapy, gene therapy using telomerase promoter-driven expression of a suicide gene, and chemicals that block telomerase biogenesis. ${ }^{33,80,81}$ Among the natural compounds, anthraquinone ${ }^{82}$ and wogonin (extract from Scutellaria baicalensis) ${ }^{83}$ appear as promising anti-tumor agents that inhibit telomerase activity.

In contrast to the physiological shortening of telomeres related to natural aging, numerous studies show the importance of lifestyle and health promotion practices in restoring the telomere-telomerase complex, ${ }^{84}$ such as regular physical activity, ${ }^{85}$ balanced diet, ${ }^{86}$ quality sleep, ${ }^{87}$ body weight control, ${ }^{88}$ meditation, ${ }^{89}$ and spiritual and religious practices, ${ }^{90}$ which provide for telomere homeostasis and the consequent balance of various cellular functions, thereby preventing diseases and other somatic and psychic disorders.

\section{Philosophical-Scientific Correlation between Vital Force and Telomeres}

The characteristics and properties of the previously mentioned telomeres expand understanding of the gene expression mechanism at the chromosome level (DNA molecule or genomic unit) and reiterate the philosophical-scientific correlations between the vital principle and the genome described in previous studies. ${ }^{1,2}$

Among these analogies, we highlight that the vital force and chromosomes are the substrates for maintaining the phenomenon of life, and the integrity of the organic vital force and the chromosomal endings (telomeres) are responsible for cellular vitality, longevity and health maintenance, whilst cellular senescence, biological aging and the disease process result from vital imbalance and alteration in TL.

Diseases and health disorders originate in vital dystonia or in the dysfunction of chromosomal replication (telomeres) in cell division, and homeostasis of vital force and telomeres are generally affected by the same etiopathogenic factors (such as inadequate habits and lifestyle, pollution and irradiation, medications and hormones, inflammation, stress and emotions).

Just as health promotion practices work to restore vital force homeostasis and telomeres, the integrity of organic vital force and telomeres can also be achieved by traditional vitalist treatments such as homeopathy. Although vital rebalancing is implicit in the philosophical conception of this therapeutic approach, there are no studies in the literature that specifically correlate the vital homeopathic phenomenon with the telomeric phenomenon.

\section{Use of Telomere Length As a Biomarker of Organic Vital Force State and Homeopathic Treatment Effectiveness}

Just as he suggested, in 1997, the "gene regulatory homeopathic hypothesis", ${ }^{17-19}$ later reiterated in numerous experimental studies, ${ }^{1,91}$ Khuda-Bukhsh proposed, in 2002, “a careful study of telomerase activity in these experimental studies to help in understanding the underlying genetic mechanism". 92

In accordance with this suggestion, experimental evidence-based studies show the role of potentized homeopathic medicines in modulating $\mathrm{TL}^{93,94}$ and telomerase activity (expression of TERT), ${ }^{95,96}$ suggesting that the telomere-telomerase complex can be a biological marker of the organic vital force state and could be used to evaluate the effectiveness of homeopathic treatment.

Working as a quantitative laboratory analysis method of cellular vitality, biological aging, and the health-disease process, evaluating the TL of leukocyte DNA extracted from peripheral blood could provide parameters of clinical and dynamic health and well-being that can be used as a diagnostic and prognostic method of the illness process, ${ }^{97-100}$ as well as in measuring the effectiveness of various therapies and health promotion practices, as previously described.

Some methods have been developed to measure TL in cells and tissues, including: Southern blot (SB) analysis of the terminal restriction fragments; quantitative PCR (qPCR), whose output is expressed as the ratio of telomere product relative to a single copy gene product; fluorescent in situ hybridization (FISH) techniques, including quantitative FISH based on microscopy and FISH using flow cytometry; single telomere length analysis and telomere shortest length assay measurements at the single telomere level, based on a combination of PCR and SB. There is an ongoing debate as to which TL measurement method is optimal in epidemiological settings, mainly between SB and qPCR. The advantages of the qPCR method are its high throughput and low cost, whilst the SB (considered the "gold standard") yields both mean TL values and generates the distribution of TLs in the DNA sample. ${ }^{101,102}$

Based on tissue type and collection methods, several specimen types have been used for TL measurement (including whole blood, buccal swabs, and cord blood). Each specimen type has relative advantages and challenges and may be differentially relevant to a specific outcome or factor being examined in relation to TL due to cell-type differences. ${ }^{101,102}$

Whole blood in circulation is one of the most often reported specimens utilized in telomere research because it is relatively easy to obtain, and so a significant number of past and current epidemiological and population studies have used it for TL measurement. When cell-type specificity is important, cell sorting methods can be used to separate out 
specific cell types from peripheral blood mononuclear cells. $^{101,102}$

Mean TL in human leukocyte DNA samples reflects the different TLs at the ends of the 23 chromosomes and in an admixture of cells. Regardless of the analysis method, the individual mean leukocyte telomere length (mLTL) presents very little variation over 1 year, provided that internal and external influences remain constant. ${ }^{103}$ Moreover, individuals with comparable mLTL display different LTL distribution (LTLD) shapes which are stable over a long time (8 years), indicating that LTLD shape may be characteristic of each individual: "Individuals with comparable mLTLs displayed different shapes of LTLDs. Inter-individual variation in LTLD shape was much larger than intra-individual variation in LTLD shape between baseline and follow-up leukocyte samples. These results show an important individual stability of LTLD shape over time, thus indicating that each individual has a characteristic LTLD signature". ${ }^{104}$

Reiterating the individualizing characteristic of the vital principle, intra-individual stability of MLTL and LTLD shape over time supports the proposal to employ sequential and periodic individual measures of LTL as a hypothetical diagnostic method of the individual's vital force state; whilst mLTL stability would indicate balance in the vital force and maintenance of a healthy state, a significant change in mLTL would indicate an imbalance in vital force (the primary cause of diseases) and corresponding manifestation of future diseases.

Analogously, the intra-individual analysis of the mLTL before, during, and after homeopathic treatment could be used as a possible biological marker of homeopathic treatment effectiveness, assisting the homeopathic clinician to analyze the various parameters of the therapy, such as individualization of the drug, doses, and homeopathic potencies, among other aspects.

In the specific case of the "isopathic use of auto-sarcode of DNA as anti-miasmatic homeopathic medicine and modulator of gene expression", 1,2 we assume that intra-individual analysis of mLTL could be a method of great sensitivity and specificity for evaluating the safety and effectiveness of treatment.

\section{Conclusions}

The homeopathic philosophical vitalist concept considers vital force dystonia as the primary cause of diseases, while the return to health status would occur by vital rebalancing. The homeopathic model expands understanding of the etiopathogenic dynamics, and also considers the manifestation of chronic miasmas (manifest psora) as a fundamental cause of chronic diseases in general, while health restoration would occur through modulating this miasmatic manifestation (latent psora).

According to the biomedical etiopathogenic process, the primary cause of diseases is the expression of genes responsible for the respective physiological disorders, considering the manifestation of disease-promoting epigenetic alterations as a fundamental cause of chronic diseases in general.
The return to health status would occur through modulating these epigenetic manifestations and consequent inhibition of pathological gene expression.

Having presented similar characteristics and properties in recent studies, ${ }^{1,2}$ we are now suggesting philosophicalscientific correlations between vital force and genome (exome plus epigenome) and between chronic miasms and epigenetic alterations that promote diseases, meaning that the genome would be the biological representation of organic vital force, and disease-promoting epigenetic alterations would be the biological representation of chronic miasms.

The properties and functions of the telomere-telomerase complex expand understanding of the gene expression mechanism at the chromosome level (DNA molecule or genomic unit) and reiterate the supposed philosophicalscientific correlations between the vital principle and the genome in view of its recognized role as a biomarker of cellular vitality, biological aging, and the health-disease process. In this hypothetical context, TL would indicate the organic vital force state and could be used in the diagnosis and prognosis of diseases according to the vitalist approach, expanding the spectrum and scope of classic homeopathic semiology.

On the other hand, the telomere-telomerase complex could also be used as a possible biomarker of the effectiveness of homeopathic treatment, employing the intra-individual analysis of the MLTL (and/or the telomerase activity) before, during, and after therapeutic interventions.

If this hypothesis were experimentally confirmed, with these periodic evaluations, homeopathic practice and clinical research could be enhanced via objective and quantitative analysis parameters accepted by the biomedical model, without the vitalist and philosophical aspects of the homeopathic health-disease process being neglected, nor the individualizing premises of homeopathic treatment being disrespected.

\section{Highlights}

- The homeopathic vital force is a philosophical nonmaterial substrate, theoretically responsible for maintaining the physiological homeostasis and the body's health state.

- The body's vital functions are controlled by biochemical information contained in the cell genome (exome plus epigenome).

- In line with the similarity of existing characteristics and properties, we suggested that the cell genome can be considered as the biological representation of the organic vital force.

- Telomere length plays an important role in maintaining cellular vitality, biological longevity, and physiological homeostasis.

- Analysis of the intra-individual telomere length might be used as a biological marker of organic vital force state and of homeopathic treatment effectiveness.

Conflict of Interest

None declared. 


\section{References}

1 Teixeira MZ. Isopathic use of auto-sarcode of DNA as antimiasmatic homeopathic medicine and modulator of gene expression? Homeopathy 2019;108:139-148

2 Teixeira MZ. Correlation between vitalism and genetics according to the paradigm of complexity. Homeopathy 2020; 109:30-36

3 Teixeira MZ. A concepção vitalista de Samuel Hahnemann. Rev Homeopatia (São Paulo) 1996;61:39-44

4 Teixeira MZ. A natureza imaterial do homem: estudo comparativo do vitalismo homeopático com as principais concepções médicas e filosóficas. São Paulo: Editorial Petrus, 2000. Accessed November 3, 2020 at: https://www.homeozulian.med.br/homeozulian_visualizarlivroautor.asp?id $=4$

5 Hahnemann S. Organon der Heilkunst. Organon da arte de curar. 6th ed. Translated by Edméa Marturano Villela and Izao Carneiro Soares Ribeirão Preto: Museu de Homeopatia Abrahão Brickmann; 1995. Accessed November 03, 2020 at: http://homeoint. org/books4/organon/index.htm

6 Teixeira MZ. Antropologia Médica Vitalista: uma ampliação ao entendimento do processo de adoecimento humano. Rev Med (São Paulo) 2017;96:145-158

7 Hahnemann S. The chronic diseases, their peculiar nature and their homeopathic cure. Translated from the second enlarged German edition of 1835 by Prof. Louis H. Tafel. With annotations by Richard Hughes. Edited by Pemberton Dudley Accessed October 26, 2020 at: http://homeoint.org/books/hahchrdi/index.htm

8 Costa EBO, Pacheco C. Epigenética: regulação da expressão gênica em nível transcricional e suas implicações. Semin Cienc Biol Saude 2013;34:125-136

9 Schultz MD, He Y, Whitaker JW, et al. Human body epigenome maps reveal noncanonical DNA methylation variation. Nature 2015;523:212-216

10 Crews D, Gillette R, Scarpino SV, Manikkam M, Savenkova MI, Skinner MK. Epigenetic transgenerational inheritance of altered stress responses. Proc Natl Acad Sci U S A 2012;109:9143-9148

11 Jirtle RL, Skinner MK. Environmental epigenomics and disease susceptibility. Nat Rev Genet 2007;8:253-262

12 Waggoner D. Mechanisms of disease: epigenesis. Semin Pediatr Neurol 2007;14:7-14

13 Santos-Rebouças CB, Pimentel MM. Implication of abnormal epigenetic patterns for human diseases. Eur J Hum Genet 2007;15:10-17

14 Esteller M. Epigenetics in cancer. N Engl J Med 2008; 358:1148-1159

15 García R, Ayala PA, Perdomo SP. Epigenética: definición, bases moleculares e implicaciones en la salud y en la evolución humana. Rev Cienc Salud 2012;10:59-71

16 Nestler EJ, Peña CJ, Kundakovic M, Mitchell A, Akbarian S. Epigenetic basis of mental illness. Neuroscientist 2016; 22:447-463

17 Khuda-Bukhsh AR. Potentized homoeopathic drugs act through regulation of gene-expression: a hypothesis to explain their mechanism and pathways of action in vitro. Complement Ther Med 1997;5:43-46

18 Khuda-Bukhsh AR. Towards understanding molecular mechanisms of action of homeopathic drugs: an overview. Mol Cell Biochem 2003;253:339-345

19 Khuda-Bukhsh AR. Current trends in high dilution research with particular reference to gene regulatory hypothesis. Nucleus 2014;57:3-17

20 Dei A, Bernardini S. Hormetic effects of extremely diluted solutions on gene expression. Homeopathy 2015;104:116-122

21 Bellavite P, Signorini A, Marzotto M, Moratti E, Bonafini C, Olioso D. Cell sensitivity, non-linearity and inverse effects. Homeopathy 2015;104:139-160
22 Zakian VA. The ends have arrived. Cell 2009;139:1038-1040

23 Blackburn EH. Telomeres and telomerase: the means to the end (Nobel lecture). Angew Chem Int Ed Engl 2010;49:7405-7421

24 Pfeiffer V, Lingner J. Replication of telomeres and the regulation of telomerase. Cold Spring Harb Perspect Biol 2013;5:a010405

25 Maestroni L, Matmati S, Coulon S. Solving the Telomere Replication Problem. Genes (Basel) 2017;8:E55

26 Saretzki G. Telomeres, telomerase and ageing. Subcell Biochem 2018;90:221-308

27 Cong YS, Wright WE, Shay JW. Human telomerase and its regulation. Microbiol Mol Biol Rev 2002;66:407-425

28 Nicholls C, Li H, Wang JQ Liu JP. Molecular regulation of telomerase activity in aging. Protein Cell 2011;2:726-738

29 Dracxler RC, Oh C, Kalmbach K, et al. Peripheral blood telomere content is greater in patients with endometriosis than in controls. Reprod Sci 2014;21:1465-1471

30 Giardini MA, Segatto M, da Silva MS, Nunes VS, Cano MI. Telomere and telomerase biology. Prog Mol Biol Transl Sci 2014;125:1-40

31 Maciejowski J, de Lange T. Telomeres in cancer: tumour suppression and genome instability. Nat Rev Mol Cell Biol 2017; 18:175-186

32 Shay JW, Wright WE. Telomeres and telomerase: three decades of progress. Nat Rev Genet 2019;20:299-309

33 Martínez P, Blasco MA. Telomere-driven diseases and telomeretargeting therapies. J Cell Biol 2017;216:875-887

34 Haycock PC, Heydon EE, Kaptoge S, Butterworth AS, Thompson A, Willeit P. Leucocyte telomere length and risk of cardiovascular disease: systematic review and meta-analysis. BMJ 2014;349:g4227

35 Zhan Y, Hägg S. Telomere length and cardiovascular disease risk. Curr Opin Cardiol 2019;34:270-274

36 Aviv A, Kark JD, Susser E. Telomeres, atherosclerosis, and human longevity: a causal hypothesis. Epidemiology 2015;26:295-299

37 Herrmann W, Herrmann M. The importance of telomere shortening for atherosclerosis and mortality. J Cardiovasc Dev Dis 2020;7:E29

38 Tellechea ML, Pirola CJ. The impact of hypertension on leukocyte telomere length: a systematic review and meta-analysis of human studies. J Hum Hypertens 2017;31:99-105

39 Jin X, Pan B, Dang X, Wu H, Xu D. Relationship between short telomere length and stroke: a meta-analysis. Medicine (Baltimore) 2018;97:e12489

40 Willeit P, Raschenberger J, Heydon EE, et al. Leucocyte telomere length and risk of type 2 diabetes mellitus: new prospective cohort study and literature-based meta-analysis. PLoS One 2014;9:e112483

41 Wang J, Dong X, Cao L, et al. Association between telomere length and diabetes mellitus: a meta-analysis. J Int Med Res 2016; 44:1156-1173

42 Lee YH, Jung JH, Seo YH, et al. Association between shortened telomere length and systemic lupus erythematosus: a metaanalysis. Lupus 2017;26:282-288

43 Lee YH, Bae SC. Association between shortened telomere length and rheumatoid arthritis: a meta-analysis. Z Rheumatol 2018; 77:160-167

44 Muneer A, Minhas FA. Telomere biology in mood disorders: an updated, comprehensive review of the literature. Clin Psychopharmacol Neurosci 2019;17:343-363

45 Pisanu C, Tsermpini EE, Skokou M, et al. Leukocyte telomere length is reduced in patients with major depressive disorder. Drug Dev Res 2020;81:268-273

46 Fani L, Hilal S, Sedaghat S, et al. Telomere length and the risk of Alzheimer's disease: the Rotterdam study. J Alzheimers Dis 2020;73:707-714

47 Miranda DM, Rosa DV, Costa BS, et al. Telomere shortening in patients with drug-resistant epilepsy. Epilepsy Res 2020; 166:106427 
48 Herrmann M, Pusceddu I, März W, Herrmann W. Telomere biology and age-related diseases. Clin Chem Lab Med 2018; 56:1210-1222

49 Hearps AC, Angelovich TA, Jaworowski A, Mills J, Landay AL, Crowe SM. HIV infection and aging of the innate immune system. Sex Health 2011;8:453-464

50 Dalzini A, Petrara MR, Ballin G, Zanchetta M, Giaquinto C, De Rossi A. Biological aging and immune senescence in children with perinatally acquired HIV. J Immunol Res 2020; 2020:8041616

51 Salimi S, Hamlyn JM. COVID-19 and crosstalk with the hallmarks of aging. J Gerontol A Biol Sci Med Sci 2020;75:e34-e41

52 Maremanda KP, Sundar IK, Li D, Rahman I. Age-dependent assessment of genes involved in cellular senescence, telomere and mitochondrial pathways in human lung tissue of smokers, COPD and IPF: associations with SARS-CoV-2 COVID-19 ACE2-TMPRSS2-Furin-DPP4 axis. Front Pharmacol 2020; 11:584637

53 Aviv A. Telomeres and COVID-19. FASEB J 2020;34:7247-7252

54 Müezzinler A, Mons U, Dieffenbach AK, et al. Body mass index and leukocyte telomere length dynamics among older adults: results from the ESTHER cohort. Exp Gerontol 2016;74:1-8

55 Cheng YY, Kao TW, Chang YW, et al. Examining the gender difference in the association between metabolic syndrome and the mean leukocyte telomere length. PLoS One 2017;12: e0180687

56 Zhang J, Rane G, Dai X, et al. Ageing and the telomere connection: an intimate relationship with inflammation. Ageing Res Rev 2016;25:55-69

57 Müezzinler A, Mons U, Dieffenbach AK, et al. Smoking habits and leukocyte telomere length dynamics among older adults: results from the ESTHER cohort. Exp Gerontol 2015;70:18-25

58 Martins de Carvalho L, Wiers CE, Manza P, et al. Effect of alcohol use disorder on cellular aging. Psychopharmacology (Berl) 2019; 236:3245-3255

59 Tannous J, Mwangi B, Hasan KM, et al. Measures of possible allostatic load in comorbid cocaine and alcohol use disorder: brain white matter integrity, telomere length, and anti-saccade performance. PLoS One 2019;14:e0199729

60 Sanei B, Zavar Reza J, Momtaz M, Azimi M, Zare Sakhvidi MJ. Occupational exposure to particulate matters and telomere length. Environ Sci Pollut Res Int 2018;25:36298-36305

61 Epel ES, Prather AA. Stress, telomeres, and psychopathology: toward a deeper understanding of a triad of early aging. Annu Rev Clin Psychol 2018;14:371-397

62 Mayer SE, Prather AA, Puterman E, et al. Cumulative lifetime stress exposure and leukocyte telomere length attrition: the unique role of stressor duration and exposure timing. Psychoneuroendocrinology 2019;104:210-218

63 Humphreys KL, Esteves K, Zeanah CH, Fox NA, Nelson CA III, Drury SS. Accelerated telomere shortening: tracking the lasting impact of early institutional care at the cellular level. Psychiatry Res 2016;246:95-100

64 Coimbra BM, Carvalho CM, Moretti PN, Mello MF, Belangero SI. Stress-related telomere length in children: a systematic review. J Psychiatr Res 2017;92:47-54

65 Ridout KK, Levandowski M, Ridout SJ, et al. Early life adversity and telomere length: a meta-analysis. Mol Psychiatry 2018; 23:858-871

66 Chae DH, Wang Y, Martz CD, et al. Racial discrimination and telomere shortening among African Americans: the Coronary Artery Risk Development in Young Adults (CARDIA) Study. Health Psychol 2020;39:209-219

67 Raynaud CM, Sabatier L, Philipot O, Olaussen KA, Soria JC. Telomere length, telomeric proteins and genomic instability during the multistep carcinogenic process. Crit Rev Oncol Hematol 2008;66:99-117
68 Meena J, Rudolph KL, Günes C. Telomere dysfunction, chromosomal instability and cancer. Recent Results Cancer Res 2015; 200:61-79

69 Srinivas N, Rachakonda S, Kumar R. Telomeres and telomere length: a general overview. Cancers (Basel) 2020;12:558

70 Song N, Li Z, Qin N, et al. Shortened leukocyte telomere length associates with an increased prevalence of chronic health conditions among survivors of childhood cancer: a report from the St. Jude Lifetime Cohort. Clin Cancer Res 2020;26:2362-2371

71 Welzl K, Kern G, Mayer G, et al. Effect of different immunosuppressive drugs on immune cells from young and old healthy persons. Gerontology 2014;60:229-238

72 Yepuri G, Sukhovershin R, Nazari-Shafti TZ, Petrascheck M, Ghebre YT, Cooke JP. Proton pump inhibitors accelerate endothelial senescence. Circ Res 2016;118:e36-e42

73 Zeng JB, Liu HB, Ping F, Li W, Li YX. Insulin treatment affects leukocyte telomere length in patients with type 2 diabetes: 6year longitudinal study. J Diabetes Complications 2019; 33:363-367

74 Maeda T, Horiuchi T, Makino N. Telomere shortening velocity of patients administered with hypnotics is accelerated in a genderdifferential manner. Can J Physiol Pharmacol 2020. Doi: 10.1139/ cjpp-2020-0291

75 Townsley DM, Dumitriu B, Liu D, et al. Danazol treatment for telomere diseases. N Engl J Med 2016;374:1922-1931

76 Liu J, Ge Y, Wu S, et al. Association between antidiabetic agents use and leukocyte telomere shortening rates in patients with type 2 diabetes. Aging (Albany NY) 2019;11:741-755

77 Lundberg M, Biernacka JM, Lavebratt C, et al. Expression of telomerase reverse transcriptase positively correlates with duration of lithium treatment in bipolar disorder. Psychiatry Res 2020;286:112865

78 Tsoukalas D, Fragkiadaki P, Docea AO, et al. Discovery of potent telomerase activators: Unfolding new therapeutic and antiaging perspectives. Mol Med Rep 2019;20:3701-3708

79 Souza-Monteiro JR, Arrifano GPF, Queiroz AIDG, et al. Antidepressant and antiaging effects of Açaí (Euterpe oleracea Mart.) in mice. Oxid Med Cell Longev 2019;2019:3614960

80 Trybek T, Kowalik A, Góźdź S, Kowalska A. Telomeres and telomerase in oncogenesis. Oncol Lett 2020;20:1015-1027

81 Seimiya H. Crossroads of telomere biology and anticancer drug discovery. Cancer Sci 2020;111:3089-3099

82 Siddamurthi S, Gutti G, Jana S, Kumar A, Singh SK. Anthraquinone: a promising scaffold for the discovery and development of therapeutic agents in cancer therapy. Future Med Chem 2020; 12:1037-1069

83 Kumar R, Harilal S, Parambi DGT, et al. Fascinating chemo preventive story of wogonin: a chance to hit on the head in cancer treatment. Curr Pharm Des 2020. Doi: $10.2174 / 1385272824999200427083040$

84 Qiao S, Jiang Y, Li X. the impact of health promotion interventions on telomere length: a systematic review. Am J Health Promot 2020;34:633-647

85 Semeraro MD, Smith C, Kaiser M, et al. Physical activity, a modulator of aging through effects on telomere biology. Aging (Albany NY) 2020;12:13803-13823

86 Canudas S, Becerra-Tomás N, Hernández-Alonso P, et. al. Mediterranean diet and telomere length: a systematic review and meta-analysis. Adv Nutr 2020;11:1544-1554

87 Iloabuchi C, Innes KE, Sambamoorthi U. Association of sleep quality with telomere length, a marker of cellular aging: a retrospective cohort study of older adults in the United States. Sleep Health 2020;6:513-521

88 Davis SK, Xu R, Khan RJ, Gaye A. Adiposity and leukocyte telomere length in US adults by sex-specific race/ethnicity: National Health and Nutrition Examination Survey. Ethn Dis 2020;30:441-450 
89 Schutte NS, Malouff JM, Keng SL. Meditation and telomere length: a meta-analysis. Psychol Health 2020;35:901-915

90 Anyfantakis D, Symvoulakis EK, Lionis CD. Religiosity, well-being and 'slowing down' ageing damage: a literature review. Cureus 2020;12:e9910

91 Khuda-Bukhsh AR. An overview of research at University of Kalyani in exploring some basic issues of homoeopathy. Indian J Res Homeopathy 2017;11:147-157

92 Biswas SJ, Khuda-Bukhsh AR. Effect of a homeopathic drug, Chelidonium, in amelioration of p-DAB induced hepatocarcinogenesis in mice. BMC Complement Altern Med 2002;2:4

93 Pathak S, Multani AS, Banerji P, Banerji P. Ruta 6 selectively induces cell death in brain cancer cells but proliferation in normal peripheral blood lymphocytes: a novel treatment for human brain cancer. Int J Oncol 2003;23:975-982

94 Frenkel M, Mishra BM, Sen S, et al. Cytotoxic effects of ultra-diluted remedies on breast cancer cells. Int J Oncol 2010;36:395-403

95 Mondal J, Das J, Shah R, Khuda-Bukhsh AR. A homeopathic nosode, Hepatitis $C 30$ demonstrates anticancer effect against liver cancer cells in vitro by modulating telomerase and topoisomerase II activities as also by promoting apoptosis via intrinsic mitochondrial pathway. J Integr Med 2016;14:209-218

96 Khuda-Bukhsh AR, Mondal J, Shah R. Therapeutic potential of HIV nosode 30c as evaluated in A549 lung cancer cells. Homeopathy 2017;106:203-213
97 Ennour-Idrissi K, Maunsell E, Diorio C. Telomere length and breast cancer prognosis: a systematic review. Cancer Epidemiol Biomarkers Prev 2017;26:3-10

98 Fasching CL. Telomere length measurement as a clinical biomarker of aging and disease. Crit Rev Clin Lab Sci 2018; 55:443-465

99 Gorenjak V, Akbar S, Stathopoulou MG, Visvikis-Siest S. The future of telomere length in personalized medicine. Front Biosci 2018;23:1628-1654

100 Mehrez F, Bougatef K, Monache ED, et al. Telomere length measurement in tumor and non-tumor cells as a valuable prognostic for tumor progression. Cancer Genet 2019;238:50-61

101 Lai TP, Wright WE, Shay JW. Comparison of telomere length measurement methods. Philos Trans R Soc Lond B Biol Sci 2018; 373:20160451

102 Lin J, Smith DL, Esteves K, Drury S. Telomere length measurement by qPCR-summary of critical factors and recommendations for assay design. Psychoneuroendocrinology 2019;99:271-278

103 Kim S, Sandler DP, Carswell G, Weinberg CR, Taylor JA. Reliability and short-term intra-individual variability of telomere length measurement using monochrome multiplexing quantitative PCR. PLoS One 2011;6:e25774

104 Toupance S, Villemonais D, Germain D, Gegout-Petit A, Albuisson $\mathrm{E}$, Benetos A. The individual's signature of telomere length distribution. Sci Rep 2019;9:685 